\title{
A Roadmap Towards Predictive HR Analytics
}

*Piya Majumder, **Sayani Mukherjee, ***Prasenjit Kundu

\begin{abstract}
The incorporation of Human Resource (HR) analytics by modern day organizations is turning out to be a progressive manoeuvre for gathering, deciphering and estimating organizational data relating to HR.HR analytics takes a holistic approach which enables not only collection, interpretation and measurement of data by using various statistical methods but also involves data forecasting. HR analytics acts as a tool for edifying well approximated solutions to complex organizational problems.HR analytics helps a company to achieve its competitive edge by formulating a productive and dynamic HR strategy in perfect synchronization with the overall business strategy of the company thereby helping it to take explicit and meticulous decisions.HR analytics has through its Business Intelligence, set of theories, methodologies, architecture, transcription of raw data into meaningful data has ushered an evolution for HR Professionals across all levels and made analytical literacy the need of the hour for achieving the corporate goals of the organization as well as improve the overall organizational performance optimally. This paper aims to find out the benefits firms would experience as an outcome of implementing and using HR analytics in contrast to using traditional HRIS for maintaining transparency in workforce information, data driven decision making and empowering Learning and development within the organization
\end{abstract}

Keywords: Human Resource Analytics, Business Strategies, HRIS

*Piya Majumder, MBA Student of Institute of Management, Kolkata, India, Email:pimpi.iem@gmail.com

**Sayani Mukherjee, Faculty, Dept of Management Studies, JIS University, Kolkata, India

Email: sayani.1993.mukherjee@gmail.com

*** Prasenjit Kundu, Associate Professor, Dept of Management, Institute of Management, Kolkata, India, Email: prasenjit.kundu@iemcal.com

ISSN Number (Print) - 2693-4108

ISSN Number (Online) - 2691-5103 


\section{Introduction}

HR Analytics demonstrates or predicts the direct impact of people data on business outcomes (George \& Kamalanabhan, 2016). Leading-edge companies are predominantly and progressively embracing sophisticated and futuristic approaches of scrutinizing and interpreting employee data to magnify their competitive advantage manifold. The corporate giants like Google and others need to ensure the highest productivity, engagement, and retention of top talent, and then replicating their successes. Hr Analytics is the only way by which we will able to forecast how much better performance we expect from our top employees-who are perhaps our greatest asset and our largest expense-we'll do well to favouring analytics over our gut instincts.

\section{Background}

Data are the new bacon of enterprise business. But as it was difficulty in collecting and analyzing HR data and also the existing HRIS systems unable to satisfy the business need. The previous research also evidence to invest in human capital (Fred \& Kinange, 2015) as the HRIS suggested. Also, in 2009 Google worked on finding out the best competent traits that are needed to be an effective manager and doing this Google developed "Project Oxygen" which caused a prodigious transition from traditional HR measurements to HR analytics. Google too pointed out the perks of using HR analytics in ameliorating organizational performances. Thou, HRIS has many great features but as HRIS workflow (Achary, 2018) is based on hard-coded business rules therefore industries are in favour of HR analytics which are based on statistical modelling and machine learning for better connect HR need.

\section{Our Approach through Case study and Data analysis}

HR analytics has been presenting high quality predictive data for risk minimization and profit maximisation which even the best of traditional HRIS has failed to present. Since HR analytics is data driven approach therefore it is less judgemental and leans more towards decision making and gives insight for gamut of HR operations like Recruitment, sometimes regarding Retention and Attrition analysis, Performance Management, Training and Development, Compensation and the other Benefits Management and overall organizational effectiveness and its 
deliverables. The crux of HR analytics is HR metrics which is a testimony that analytics is not just about numbers but it is more about astute logic and appropriate reasoning.

A quintessential HR Analytics System compiles employee data from HRIS, business performance records within a Data Warehouse, administers big data, statistical analysis and data mining techniques to analyse and interpret hidden data patterns, relations, probabilities and forecasting. A Data Warehousing System is concerned with the collection of data, analysis of the collected data, transformation and transposition and preserving data on numerous databases.

As per our studies and analysis (Pratik, 2020; Vulpen, 2019; Mohammed \& Quddus, 2019) there are multiple number of cases where the aptly executed application of HR Analytics triggered the company's vision and mission forecasting much more accurate and reliable like the below mentioned cases.

- Cognizant's a U.S.-based professional services firm with many employees in India, analyzed social media contributions, particularly blogs. It found that bloggers were more engaged and satisfied than others and performed about $10 \%$ better, on average. Their analytics clearly revealed that employees who blogged were more engaged and satisfied.

- IBM, where turnover was high for certain business-critical roles. Using IBM's Watson machine learning capabilities, the workforce analytics team build an algorithm that included sources like recruitment data, tenure, promotion history, performance, role, salary, location, job role, and more. The company likewise incorporated employee sentiment too, estimated with the aid of their Social Pulse. The hypothesis here was that engagement with social media might fall when employees are thinking about leaving. The investment yielded \$300,000,000 over four years and turnover for critical roles has fallen by $25 \%$. As far as the findings reveal, there was a boost in productivity observed while recruitment costs were reported to decline too.

\section{Gap of the study}

The main limitations of the following research transcendentally focus on the availability and accessibility of literature in the area. There are scopes for existing literature to be substantiated with more case studies of predictive analytics and in-depth organizational studies to ascertain the best roadmap is predicted.

ISSN Number (Print) - 2693-4108

ISSN Number (Online) - 2691-5103 


\section{Future Scope}

We are hopeful that future research in this direction will opens many avenues in the area of Human Resource Analytics and will address the aforesaid issues. We are waiting for the era where each of the basic or advanced HR operations including planning, staffing, performance analysis will fully automated and govern by HR analytics and traditional HRIS operations will reach to its extent heights.

\section{References:}

1. George, L., \& Kamalanabhan, T. J. (2016). A study on the acceptance of HR analytics in organisations. International Journal of Innovative Research and Development, 5(2), 357-360.

2. Fred, M. O., \& Kinange, U. M. (2015). Overview of HR Analytics to maximize Human capital investment. International Journal of Advance Research and Innovative Ideas in Education, 1(4), 118-122.

3. Achary, J. (2018). Hr analytics and Survey. Link: https://www.slideshare.net/JyothikrishnanAchary/hr-analytics-and-survey Accessed on 21.03.2021

4. Reddy, P. R., \& Lakshmikeerthi, P. (2017). HR analytics-An effective evidence based HRM tool. International Journal of Business and Management Invention, 6(7), 23-34.

5. Gupta, B. N., \& Shaikh, S. (2018). PEOPLE ANALYTICS: NOVEL APPROACH TO MODERN HUMAN RESOURCE MANAGEMENT PRACTICE. International Journal of Engineering Technologies and Management Research, 5(7), 78-83.

6. Pratik (2020). HR Analytics \& HR Strategy Improvisations from an HR Practitioner's POV - Why High Performers leave the organization? Link: https://thebrew.in/hranalytics-hr-practitioner-pov-declutter/ Accessed on 21.03.2021

7. Vulpen, Erik van (2019). 15 HR Analytics Case Studies with Business Impact. Link: https://www.analyticsinhr.com/blog/hr-analytics-case-studies/ Accessed on 21.03.2021

8. Mohammed, D., \& Quddus, A. (2019). HR ANALYTICS: A modern tool in hr for predictive decision making. Journal of Management, 6(3). 